\title{
A FILOSOFIA NA EDUCAÇÃO BÁSICA: CONCEPÇÕES E PRÁTICAS DOS PROFESSORES DO ENSINO MÉDIO
}

\author{
Wanderley da SILVA ${ }^{1}$
}

RESUMO: Este texto deriva de uma atividade prática desenvolvida na disciplina Ensino de Filosofia no ano de 2015 e tem como objetivo divulgar e refletir sobre alguns dados extraídos de uma pesquisa qualitativa com docentes de filosofia do Ensino Médio. A pesquisa buscou realizar um levantamento dos principais métodos, recursos e objetivos didáticos utilizados pelos docentes que lecionam filosofia nos municípios do Rio de Janeiro, Seropédica, Nova Iguaçu e Paracambi. Além dos dados, as análises aqui presentes buscam ajudar na elucidação do atual estágio da disciplina na Educação Básica, assim como reafirmar a importância, desafios e possibilidades da atividade filosófica na escola.

PALAVRAS-CHAVE: Filosofia. Educação básica. Didática.

\section{INTRODUÇÃO}

Neste trabalho apresentamos alguns resultados de uma pesquisa qualitativa, que buscou sistematizar algumas percepções de um conjunto de professores regentes da Educação Básica, quanto à importância da filosofia escolar e às suas abordagens didáticas na prática profissional. A pesquisa teve origem durante as aulas de ensino de filosofia em 2015, disciplina obrigatória da grade curricular da licenciatura em filosofia da Universidade Federal Rural do Rio de Janeiro (UFRRJ).

Durante o primeiro semestre de 2015, dois pontos foram destacados pelos estudantes na disciplina, durante os encontros e nas discussões teóricas em sala, a saber, o da importância da filosofia escolar, e as dificuldades didáticas da sua efetivação a bom tento. A partir da demanda dos discentes, decidimos realizar um conjunto de entrevistas para nos aproximar da percepção dos docentes em exercício na educação básica quanto a esses pontos, pois consideramos que seria uma importante fonte no processo formativo ao que os licenciandos estavam se submetendo.

Contudo, os dados trazidos do campo mostraram um potencial maior do que esperávamos inicialmente. Conforme desenvolvemos nossas análises, surgiram dados que podem contribuir para a elucidação do atual estágio da filosofia escolar, após meia década de efetivação na grade curricular nacional da Educação Básica. Mais que

1 UFRRJ - Universidade Federal Rural do Rio de Janeiro. Pós-Graduação em Educação Agrícola. Seropédica - RJ - Brasil. 23897-000 - wanderleyws17@gmail.com 
denunciar às dificuldades do exercício do magistério, fato que deve ser lembrado, as informações e análises aqui apresentadas pretendem ajudar a entender quais são as propostas didáticas em curso nas escolas, além da percepção dos docentes sobre as suas ações.

Para o nosso objetivo de elucidação, optamos por analisar as perguntas abertas oferecidas aos entrevistados, que versaram sobre suas atividades e recursos didáticos; suas perspectivas sobre o atual estágio da filosofia na escola e, por último, sobre as suas concepções filosóficas e propósitos com a disciplina. Seguidas de algumas análises, nossa finalidade foi a de trazer aos leitores algumas percepções dos docentes em serviço, como forma de melhor contribuir para a formação dos licenciandos e para o conhecimento do público interessado no tema.

\section{OS SUJEITOS DA PESQUISA E LÓCUS DE ATUAÇÃO}

Nossa pesquisa teve a participação de trinta (30) professores regentes da Educação Básica dos municípios de Seropédica, Rio de Janeiro, Paracambi e Nova Iguaçu. Todavia, só foi possível realizar a análise de quatorze (14) questionários, pois estavam completos e permitiram a avaliação das categorias pretendidas. Dos respondentes, seis (6) lecionavam no Rio de Janeiro; cinco (5) em Seropédica; dois (2) em Nova Iguaçu e um (1) em Paracambi. Desses, doze (12) trabalhavam na rede pública e apenas dois (2) na rede privada.

Para a realização da pesquisa foram feitos levantamentos nas escolas, públicas e privadas, dos municípios e contatos com os docentes para convidar à participação; apenas no caso do Rio de Janeiro, pelo grande número de escolas, a pesquisa ficou restrita à parte da zona oeste, mais especificamente ao bairro de Campo Grande e adjacências. A opção pelos munícipios e regiões acima mencionadas teve como justificativa a proximidade com o campus sede da UFRRJ, que facilitou o deslocamento e a viabilidade da pesquisa, que não contou com financiamento.

Os questionários apresentados aos respondentes foram semiestruturados com três perguntas abertas, com objetivo que cada docente pudesse explanar livremente sobre as questões propostas. Quanto ao gênero, seis (6) eram do sexo feminino e oito (08), masculino. Em relação à formação, o grupo era composto por dois (2) licenciados em História; dois (2) em Pedagogia e dez (10) em Filosofia. Esse último dado merece um esclarecimento sobre a formação do docente que leciona filosofia na Educação Básica, e, também, ressaltar a importância da Universidade no contexto local. 
Inicialmente, podemos constatar que a nossa pesquisa não reflete minimamente a relação entre formação e exercício da disciplina, uma vez que, no Ensino Médio encontramos uma grande defasagem entre formação/disciplina lecionada, conforme dados do Censo Escolar 2013. Segundo dados do Instituto Nacional de Estudos e Pesquisas Educacionais Anísio Teixeira (INEP), o Ensino Médio como um todo sofre com essa defasagem, no entanto, no caso da filosofia o caso é ainda mais evidente. Se no Ensino Médio com um todo apenas $51,7 \%$ dos professores são formados na disciplina que lecionam, no caso da filosofia, apenas $21,2 \%$ são licenciados em filosofia (INEP, 2014).

Se fossemos transformar em dados estatísticos os elementos que temos, mostraria que mais de $71 \%$ dos entrevistados possuíam formação em filosofia. Não obstante, com se trata de uma pesquisa qualitativa, apenas queremos deixar evidenciado que essa predominância de docentes formados em filosofia exercendo a disciplina na Educação Básica na região não representa uma contradição com os dados do INEP, mas provavelmente, atesta a importância do curso de licenciatura em filosofia da UFRRJ para região.

O curso de licenciatura em filosofia da UFRRJ foi criado em 2008 e entrou em funcionamento em 2009, juntamente com outros cursos de Ciências Humanas que tiveram a sua criação favorecida decisivamente pelo Programa de Apoio ao Plano de Reestruturação e Expansão das Universidades Federais (REUNI). Juntamente como o Programa de Bolsas de Iniciação à Docência (PIBID), que o subprojeto de filosofia participou desde 2010, e outras ações e pesquisa de incentivo à docência, o curso vem conquistando um caráter importante de formação e preparando profissionais que atendem aos quadros da escola pública da região. Uma forte evidência da importância do curso na região é que, do nosso conjunto de entrevistados, seis (6) dos dez (10) docentes formados em filosofia, e exercendo a disciplina na escola pública, eram egressos da UFRRJ.

Portanto, atribuímos esse dado alvissareiro, do aumento na região pesquisada de professores de filosofia lecionando a disciplina na rede pública, como um efeito das políticas públicas de fortalecimento da docência no Brasil. Feita a ressalva de que os dados aqui não têm embasamento estatístico para projetar essa tendência, apenas evidencia um possível efeito na região. Feitas essas caracterizações e observações, passamos a análise das informações prestadas pelos participantes nas três perguntas abertas. 


\section{DESCRIÇÃO DOS PRINCIPAIS MÉTODOS DIDÁTICOS USADOS NAS AULAS DE FILOSOFIA E SEUS OBJETIVOS}

Na primeira pergunta aberta aos participantes, foi pedida uma "descrição dos seus métodos pedagógicos e seus objetivos didáticos". A intenção dessa questão era a de perceber quais seriam as principais práticas didático-metodológicas, e como os docentes atribuíam objetivos a elas. Assim, usamos o Gráfico 1, para destacar as respostas, mais especificamente quais eram os instrumentos didáticos comumente utilizados pelos docentes.

Gráfico 1 - Métodos e instrumentos didáticos

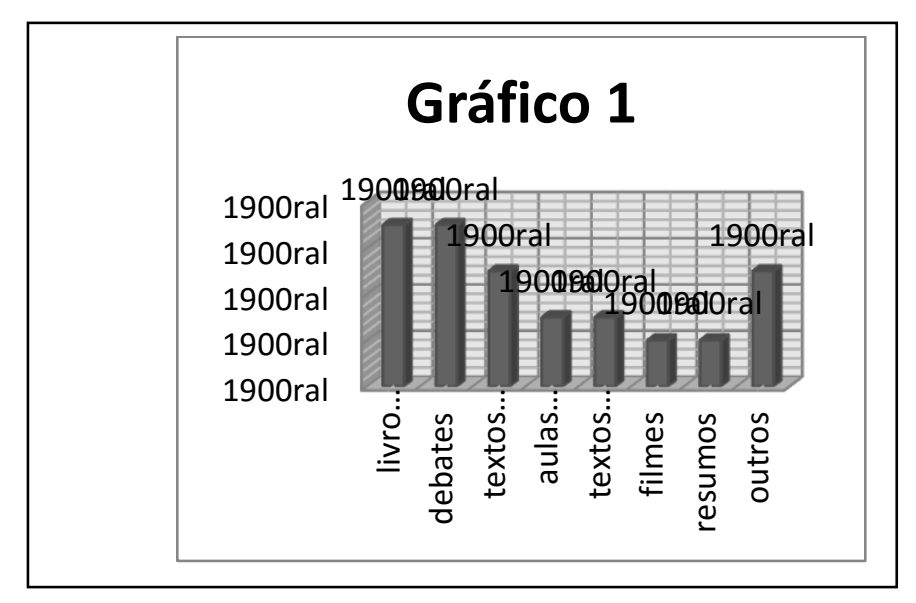

Fonte: Elaboração própria.

Conforme podemos observar, a maioria dos docentes usava livros didáticos, associados aos debates. Nas declarações dos respondentes, podemos ter uma boa perspectiva do motivo do uso desses dois recursos. A utilização dos "debates" está quase sempre associada à necessidade de "contextualização do tema com a vida dos estudantes". A professora C (usaremos letras aleatórias para manter o anonimato dos respondentes) garante que:

Evito não me perder em tantas leituras, mas procuro entender e trazer a realidade dos alunos para a sala de aula, como exemplo: debates em sala de aula sobre os temas levantados pela mídia ou até mesmo algum conflito familiar e ou interno. (Professora C).

Também as condições estruturais e a maneira como a disciplina está oferecida na escola é um dos motivos da escolha, nas palavras do professor $\mathrm{S}$. 
como vídeos, projetores, mas a escola não os tem e eu não possuo computador; daí uso o resumo para, em seguida, realizar debates, mesmo sabendo que poderia enriquecer mais. (Professor S).

E, ainda, existe uma clara percepção entre os docentes de que o debate é um importante instrumento, que pode ser propriamente filosófico, proporcionando aos discentes um contato com características da filosofia na prática argumentativa, como sugere o professor A.

[...] privilegio neste momento um método pedagógico de leitura e debate de textos filosóficos, pois acredito que, assim, os alunos podem entrar em contato e podem descobrir características do pensamento filosófico. Este método de debate e discussão que utilizo, me possibilita tornar claro aos alunos, num primeiro momento, o que é a filosofia. (Professor A).

Considerando bastante lúcidas e enriquecedoras as contribuições dos docentes, que precisam desenvolver suas atividades em condições muitas vezes aquém do mínimo necessário estruturalmente, e, ainda se deparam com um tempo reduzido na grade curricular para lecionar, parece importante pensar um pouco didaticamente na técnica do debate. Um bom debate, principalmente se tem pretensões filosóficas, demanda tempo e preparação.

O debate pode ser caracterizado como uma discussão argumentada sobre um tema bem definido. Seu objetivo não é apenas convencer o interlocutor, mas, principalmente, fundamentar suas próprias opiniões. Por esse aspecto, as formas filosóficas de diálogo, discussão e debate distinguem-se daquelas apresentadas no cotidiano; enquanto estas últimas só se interessam em saber das opiniões, as formas filosóficas perguntam pelas suas razões, implicações, pressupostos etc. $\mathrm{O}$ tema do debate deve ser estabelecido antecipadamente para que os estudantes tenham tempo para preparar-se e construir seus argumentos. (RODRIGO, 2009, p.83-84).

Diante desses relatos e análises, corre-se o risco de, pelo curto tempo destinado à disciplina e a sobrecarga que são submetidos os docentes, haver um aligeiramento da preparação e objetivos dos debates. Associado ao empenho em "contextualizar" os temas aos interesses dos estudantes, inclusive tomando temas da vida privada como material de análise pode-se estar privilegiando o improviso e os temas de outras ordens em detrimento do exercício propriamente filosófico. Essa tendência de aligeiramento de conteúdos e práticas pedagógicas parece derivar também das condições estruturais e burocráticas que as escolas adotam, pois muitas impõem ao docente uma "dupla tarefa de mestres e funcionários do Estado" que exige do professor de filosofia uma 
capacidade de ocupar o lugar, bastante difícil, "da transmissão, da provocação e do convite" (CERLETTI, 2009, p.39).

Outro aspecto que se evidenciou nessa primeira questão, foi a ampla utilização, juntamente com o recurso dos debates, do livro didático como instrumento privilegiado (Gráfico 1). A utilização do recurso também foi justificada pelos mesmos motivos, estruturais e curriculares, da opção pelo instrumento anterior. Não obstante, uma das intervenções pode trazer um dado novo para a elucidação dessa questão, trata-se da necessidade percebida pelo professor C. em relação à aceitação da disciplina na escola, principalmente pelos estudantes.

Outro fator importante que podemos citar em relação a disciplina é que, mesmo com atividades lúdicas, debates e algo que faça com que a filosofia seja um pouco mais livre comparada com as outras, tenho que assumir que não consigo uma aceitação de $100 \%$ dos alunos de acordo com o tema que foi abordado, preciso usar o livro [didático] para dar continuidade (inserção nossa). (Professor C).

É provável que a filosofia sofra com a segmentação hierárquica das disciplinas escolares. Não é incorreto afirmar que algumas disciplinas como Língua Portuguesa e Matemática possuem destaque escolar, até porque são linguagens valorizadas na sociedade, sobretudo por um viés instrumental. Ambas são laureadas com grande importância em concursos que garantem, supostamente, a ascensão social e sucesso profissional. Sem entrar na seara da discussão sobre a importância de cada área, linguagem ou disciplina, sabemos também que essa segmentação atinge outras matérias escolares, desse modo, talvez fosse mais importante pensar se haveria algum prejuízo na utilização maciça do livro didático nas aulas de filosofia.

Mesmo sendo citada a utilização de "textos clássicos" e "textos transversais", com cinco (5) e três (3) incidências, respectivamente (Gráfico 1), esses recursos seriam complementares ao livro didático. Em relação à oferta do Ministério da Educação via Programa Nacional do Livro Didático (PNLD), obtivemos um tímido aumento no universo das obras disponíveis saindo de apenas três títulos em 2011 (BRASIL, 2011) para os atuais cinco em 2015 (BRASIL, 2014).

Mesmo sendo prematuro afirmar, podemos considerar que somada às dificuldades de tempo e planejamento das atividades, com a pequena diversidade de livros didáticos disponíveis, existe também na filosofia escolar uma tendência à padronização de trechos e temas filosóficos. Tendência que merece atenção e 
discussões, que fogem ao âmbito desse trabalho, contudo, deixamos evidenciado a partir dos dados aqui analisados.

Quanto às "aulas expositivas" (3); "resumos" (2) e "filmes" (2), demonstram seguir o mesmo padrão do uso corrente no Ensino Médio, com objetivos semelhantes, isto é, sistematizar os conteúdos do Currículo Mínimo de filosofia (RIO DE JANEIRO, 2012). Já no item "outros" (Gráfico 1), foram citados, cada item como uma (1) incidência, "seminários", "filosofar", "atitudes construtivistas" e "exercícios avaliativos", que não consideramos ter uma ligação clara entre si.

Os objetivos manifestos em relação às práticas e instrumentos didáticos, segunda parte da primeira questão, estão voltados para direção semelhante, que organizamos em três grupos, a saber, a "formação crítica"; "importância da filosofia para o cotidiano" e “consciência social”, exemplificadas nas citações abaixo:

Os objetivos que busco atingir com o ensino de filosofia na educação básica se dão no sentido de proporcionar que os jovens tenham contato, de modo geral, com a história da filosofia e experiências com a filosofia. Penso que a partir dessa experiência com a filosofia, temse uma formação mais completa, crítica e humana. (Professor F.)

Utilizo textos transversais, filmes que possam aproximar a filosofia do cotidiano e da linguagem dos alunos. Com objetivo de, através de temas filosóficos, fazer os alunos compreenderem a importância da reflexão e do questionamento na formação e educação e, principalmente, no seu cotidiano. (Professor C.)

Nosso objetivo é promover um ensino pertinente às demandas socioculturais, políticas e do pensamento contemporâneo no atual contexto, que requer um olhar atento para os problemas regionais, nacionais e mundiais, atualizando as perspectivas pedagógicas afim de desenvolver nos discentes a consciência crítica, reflexiva e social. (Professora M.)

Concordamos com todas as assertivas produzidas pelos docentes. Inclusive, corroborando essas considerações, reafirmamos a importância da "contribuição" da filosofia no Ensino Médio brasileiro, que não pode deixar de ser pensada em seu contexto social-histórico. Na Lei de Diretrizes e Bases da Educação, inclusive, a filosofia, juntamente com a sociologia, ganhou status de promotora da cidadania (BRASIL, 1996). Todavia, essa centralidade ou excesso de responsabilidade da filosofia em promover a cidadania e ou o pensamento crítico, possivelmente seja menos uma característica e sim uma cavilação para a própria disciplina. Isso não significa que a 
filosofia em sala de aula não deva ser preocupar com essa questão e contextualizar seus conhecimentos (COSTESKI, 2009), mas reafirmar que essa tarefa é coletiva.

Julgamos importante reafirmar que a filosofia, ou qualquer outra disciplina escolar, não pode ceder ao chamamento de ser o lugar da criticidade ou a responsável pela promoção da cidadania, pois acaba trazendo um preocupante ônus à atividade filosófica, quanto mais na escola. Essa preocupação já estava em voga no fim da década de 2000, quando da revogação do Inciso III do art. 36 da LDB pela lei 11.684 de 2008; mas a expectativa por um papel efetivo da filosofia como construtora da cidadania, agora como disciplina obrigatória permaneceu e, aparentemente, continua ainda forte na formação do docente de filosofia (BRASIL, 2008).

Pode ser um novo caminho, para suavizar essa "herança" da definição da filosofia escolar como promotora da cidadania e do pensamento crítico, a inversão da lógica meramente disciplinar para uma nova forma de ensinar, também a filosofia escolar, ligando a filosofia com a arte e outras áreas do conhecimento (CARMINATI, 2013). De qualquer modo, fica aqui registrada a nossa preocupação e a importância da discussão desse aspecto nos cursos de licenciatura e nas formações continuadas em serviço para os docentes de filosofia.

\section{SITUAÇÃO DA FILOSOFIA NA ESCOLA}

Na segunda pergunta aberta foi solicitado aos respondentes que explanassem sobre a sua percepção de "como filosofia está se estabelecendo na escola". O objetivo dessa questão foi o de tentar perceber como os docentes estão significando a disciplina, suas dificuldades e potencialidades, na prática escolar. Dez (10) entrevistados demostraram uma perspectiva negativa do atual estabelecimento da filosofia escolar em suas práticas e perspectivas. Os outros quatro (4), mesmo não desconhecendo as dificuldades acenaram com a possibilidade de " [...] um futuro promissor para a filosofia nas escolas, como aquela disciplina mais profunda, mais fundamental que é imprescindível para a construção da autonomia.” (professor A.).

No conjunto dos relatos sobre as dificuldades para o estabelecimento da disciplina, o destaque foi à indicação da pequena carga horária que recebe a filosofia na grade curricular como principal empecilho, conforme ilustra o Gráfico 2 abaixo: 
Gráfico 2 - Dificuldades enfrentadas pela disciplina

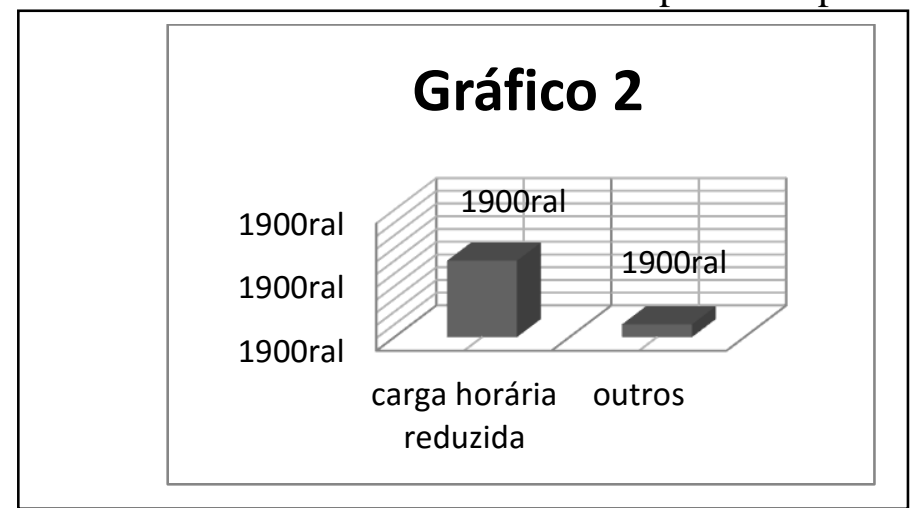

Fonte: Elaboração própria.

Provavelmente é consenso que a atual carga horária destinada à filosofia não é capaz de proporcionar um bom desenvolvimento das atividades filosóficas. Ainda assim, é importante ressaltar que a obrigatoriedade da disciplina na Educação Básica é muito recente (2008) e que a sua permanência na grade curricular sofre, e sempre sofreu ameaças de descontinuidade. Na verdade, nem podemos falar em descontinuidade, pois apesar da filosofia ter sido presente na educação brasileira desde o período colonial, ela só conseguiu o seu lugar no currículo a partir da Lei $n^{\circ} 11.684$ de 2008 , que assegurou a efetiva obrigatoriedade da disciplina no ensino médio brasileiro a partir de 2010 (BRASIL, 2008).

Se, por um lado, a obrigatoriedade da disciplina ajuda a construir um campo escolar para a filosofia, por outro, as condições estruturais e as dificuldades iniciais da sua implantação podem não garantir a sua continuidade. A perspectiva utilitarista pela qual grande parte da sociedade significa a educação, associada ao pequeno percentual de professores formados em filosofia e a tradição bacharelesca muito comum nos cursos de licenciatura, podem ajudar a construir a convicção de que a disciplina não é necessária e ou que pode ser novamente um "tema transversal”, como já vem sendo defendido por alguns grupos, inclusive a pedido do governo federal no seu esforço de construção da "unificação curricular da educação básica” (BRASIL, 2015).

Não obstante, a mera constatação das dificuldades que a filosofia enfrenta e a insatisfação atual com a sua efetiva atividade, pouco favorecerá a mudança do quadro. Por conseguinte, a manutenção e melhoria da qualidade da experiência filosófica na educação básica pode ter uma dupla frente de trabalho. Por um lado, aproximar cursos de licenciatura em filosofia da realidade e demandas das salas de aula e, ao mesmo 
tempo, travar uma batalha de convencimento político para a manutenção da disciplina e aumento da sua carga horária.

\section{CONCEPÇÃO DE FILOSOFIA DOS ENTREVISTADOS}

Partindo do suposto de que é muito importante que o docente em filosofia tenha clareza sobre a sua própria concepção filosófica, essa questão foi idealizada e apresentada aos entrevistados: "Qual a sua concepção de filosofia e seus objetivos na escola”? O resultado da primeira parte da pergunta está quantificado no Gráfico 3:

Gráfico 3 - Concepções sobre filosofia

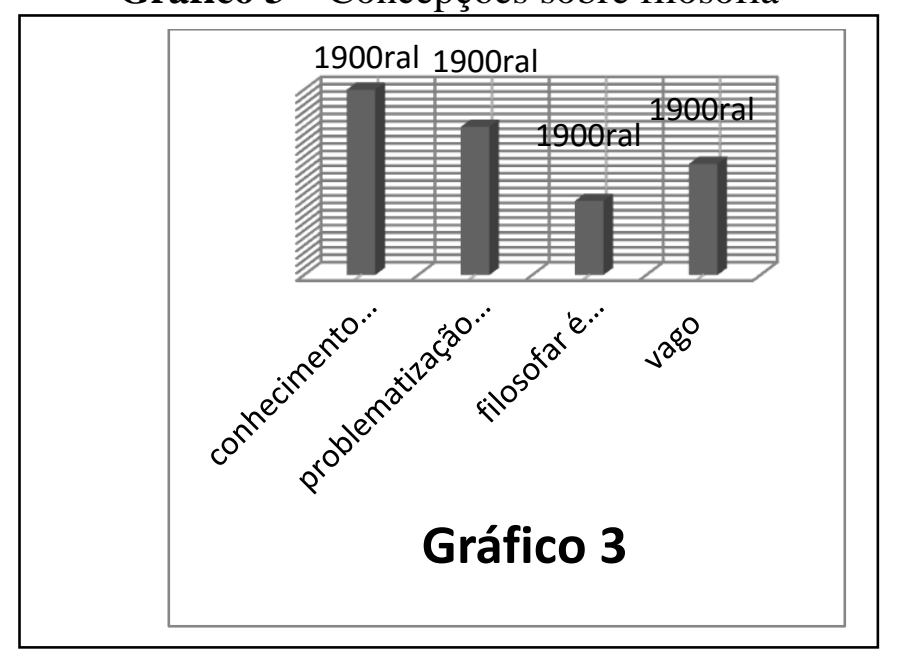

Fonte: Elaboração própria.

$\mathrm{Na}$ verdade, nosso objetivo com essa questão era o de perceber quais as bases filosóficas, fossem autores, correntes ou perspectivas que os respondentes indicavam como significativas na sua formação e atuação. Entretanto, não conseguimos nos aproximar dessa percepção, uma vez que os entrevistados preferiram tentar definir a filosofia. Sistematizamos os resultados no Gráfico 3 em três grupos de definições, já o item "vago", foi atribuído às definições que não permitiram clareza para atribuirmos um sentido mais específico, como: "é a formação que visa o desenvolvimento humano" (professor C.).

Sem sugerir qualquer tipo de padronização sobre um caminho, posição, sentido ou significado que qualquer docente deva seguir nossa convicção, entretanto, é de que a clareza do posicionamento sobre o que é a filosofia e seus objetivos seja fundamental para o exercício da atividade filosófica em qualquer ação sistematizada, sobretudo na filosofia escolar, posto que: 
Definir o conceito de filosofia é o passo fundante e, portanto, fundamental do processo de se ensinar filosofia; significa dizer, desde o início, com qual autor, com qual referencial teórico irá trabalhar na sala de aula; é assumir, enfim, uma postura filosófica em torno dos problemas filosóficos emergidos no processo de ensino.[...] Ora, independentemente da definição de filosofia, cada qual irá refletir, de forma bastante importante, como se trabalhar o ensino de filosofia, ou seja, deverá conter em si o reflexo do autor e do conceito de filosofia que se tenha como cenário. Em última instância, significa deixar às claras os referenciais teóricos imanentes ao ensino de filosofia. (DANELON, 2010, p.0187-189).

Quanto aos objetivos da filosofia no Ensino Médio, complemento da questão, surpreendentemente, obteve $100 \%$ das respostas indicando a "formação do cidadão crítico". Fosse como "posição crítica diante do mundo" (professor F.); "cidadãos capazes de exercer papel reflexivo" (professor M.) ou diretamente enunciado como formação de "um cidadão crítico" (professor C.), todas as respostas apontam para esse como objetivo fundamental da filosofia em suas práticas.

Voltando à importância do posicionamento diante de uma concepção filosófica, dizer que a formação do cidadão crítico é um objetivo, não contraria os preceitos legais, nem tampouco as convicções instituídas sobre o potencial da filosofia escolar, todavia, não qualifica a dimensão do ser crítico. Diante de uma grande diversidade de concepções filosóficas, é razoável pensar que o posicionamento docente diante da filosofia favoreça o ensino da disciplina como um "problema filosófico" (CERLETTI, 2009), já que seus objetivos são possíveis de serem perseguidos e razoavelmente atingidos com a construção de um procedimento didático, também filosoficamente problematizado, como ação filosófica. Assim, sem a clareza de sua concepção, seus objetivos parecem diluir em meio às dificuldades estruturais e conceituais.

\section{CONSIDERAÇÕES FINAIS}

Respeitando os propósitos do presente trabalho, nossa contribuição para elucidação dos limites e possibilidades do recente estabelecimento da filosofia escolar, apensar de modesta, indica algumas interessantes questões. Primeiramente, ressaltar a importância dos docentes da Educação Básica, em suas atividades diárias, que enfrentam muitas dificuldades para a implantação e manutenção da disciplina. O trabalho desses professores é fundamental para a atividade nas escolas e, suas 
considerações, preocupações e sugestões merecem prioridade em qualquer análise e planejamento para filosofia, seja na escola ou na construção de políticas públicas.

Diante das dificuldades dos professores, segundo os relatos do grupo que participou da pesquisa, evidenciou-se uma característica que merece maiores reflexões, sobretudo por parte das instituições formadoras, ou seja, a tendência à padronização do material didático. A situação da recente implantação da disciplina na Educação Básica, não veio associada a uma estrutura pedagógica necessária à disciplina escolar, que oferece via PNLD um pequeno repertório de materiais à disposição do docente da escola pública. Discordando daqueles que acreditam que basta estudar filosofia para ser tornar um professor, defendemos que é necessário construir concepções didáticas para o estabelecimento da disciplina. Essas concepções, não podem estar descoladas das características regionais e referentes culturais de cada escola, assim, o professor de filosofia precisa ter a sua formação didática robustecida.

Uma possibilidade, para ajudar o trabalho docente na Educação Básica, é o fortalecimento e incentivo nas licenciaturas de espaços para a construção de concepções e materiais didáticos, superando hábitos e práticas bacharelescas nos cursos. A insistente tradição universitária brasileira, de delegar aos departamentos ou faculdade de educação a tarefa de formar os professores nos parece equivocada. Sem dúvida que as disciplinas pedagógicas possuem sua especificidade, e exigem profissionais que se dediquem a elas, contudo, a qualificação, debate, aprofundamento e constante exercício do docente em formação é tarefa de todo o curso. Sem esse esforço coletivo, a preparação do docente torna-se pouco capaz de oferecer os recursos necessários para o início da sua prática profissional. Pois, sem uma real valorização da atividade profissional desse docente, desde sua formação, poucos conseguem se sentir autores de suas produções, principalmente didáticas.

Também ficaram evidenciadas as dificuldades referentes à pequena carga horária da disciplina no currículo e da falta de uma clara perspectiva da concepção filosófica adotada pelos mestres. Sobre a carga horária, naturalmente, depende de uma nova ação de fortalecimento para a disciplina, conquistando os vários setores da sociedade em razão da importância da atividade filosófica na Educação Básica e, posteriormente, materializando essa importância em novo rearranjo nas políticas públicas.

Já o que diz respeito propriamente à clareza das concepções filosóficas e dos seus objetivos na disciplina escolar, o estudo nos ajuda a perceber que essas questões devem ser uma preocupação no processo formativo do docente. Reafirmar a formação 
docente em filosofia pode ajudar a criação de um espaço de reflexão sobre a didática e o ensino como problemas eminentemente filosóficos, fazendo com que esse profissional já traga claramente suas posições e confronte criticamente seus objetivos frente ao que propõe a legislação, superando reprodução de noções que pouco contribuiu com a atividade filosófica.

Enfim, pela novidade da disciplina na escola e sua importância, tanto para criação de um campo profissional para os docentes quanto para construir um espaço de contato e reflexão filosófica para os jovens, os problemas e dificuldades da implantação da filosofia não podem estar revestidos de mero pessimismo. Sem dúvida as dificuldades existem, mas o próprio estabelecimento da filosofia na Educação Básica como disciplina merece os maiores e melhores esforços para sua manutenção e aprimoramento, que só poderão acontecer com a participação coletiva, inclusive de outra lógica que supere as práticas que não favorecem o filosofar.

\section{PHILOSOPHY IN BASIC EDUCATION: CONCEPTS AND PRACTICES SECONDARY SCHOOL TEACHERS}

ABSTRACT: This text derives from a practical activity developed in discipline Philosophy Teaching in 2015 and aims to disseminate and reflect on some data extracted from a qualitative survey with high school philosophy teachers. The research sought to conduct a survey of the main methods, resources and teaching goals used by teachers who teach philosophy in the municipalities of Rio de Janeiro, Seropédica, Nova Iguaçu and Paracambi. Besides the data, the analyzes presented here seeking help in elucidating the current stage of discipline in basic education, as well as to reaffirm the importance, challenges and possibilities of philosophical activity at school.

KEYWORDS: Philosophy. Basic education. Didactics.

\section{REFERÊNCIAS}

. Ministério da Educação e Cultura. Base Nacional Comum Curricular.

Brasília, 2015.

. Ministério da Educação. Secretaria de Educação Básica. Guia de livros

didáticos: PNLD 2015: Filosofia: ensino médio. Brasília, 2014.

. Ministério da Educação. Secretaria de Educação Básica. Guia de livros

didáticos: PNLD 2012: Filosofia. Brasília, 2011. 
Ministério da Educação e Cultura. Lei n ${ }^{\circ} 11.684$, de 02 de junho de 2008.

Altera o art. 36 da Lei no 9.394, de 20 de dezembro de 1996, que estabelece as diretrizes e bases da educação nacional, para incluir a Filosofia e a Sociologia como disciplinas obrigatórias nos currículos do ensino médio. Diário Oficial da União, Brasília, 03 jun. 2008.

Ministério da Educação. Lei no 9.394, de 20 de dezembro de 1996. Estabelece as diretrizes e bases da educação nacional. Diário Oficial da União, Brasília, 20 dez. 1996. Disponível em:

<http://portal.mec.gov.br/seed/arquivos/pdf/tvescola/leis/lein9394.pdf >. Acesso em: 28 ago. 2015.

CARMINATI, C. J. Formação e didática do ensino da Filosofia. Revista Diálogo Educacional, Curitiba, v.13, n. 38, p.369-384, jan./abr. 2013.

CERLETTI, A. O ensino de Filosofia como problema filosófico. Belo Horizonte: Autêntica, 2009.

COSTESKI, E. Epistemologias e tecnologias para o ensino das humanidades. Fortaleza: Tiprogresso, 2009. Fascículo 3: O ensino de Filosofia.

DANELON, M. Em torno da especificidade da filosofia: uma leitura das orientações curriculares nacionais de filosofia para o Ensino Médio. In: CORNELLI, M.;

CARVALHO, M., DANELON, M. Filosofia: ensino médio. Brasília: Ministério da Educação, 2010. (Coleção Explorando o Ensino ; v. 14). p.185-202.

INSTITUTO NACIONAL DE ESTUDOS E PESQUISAS EDUCACIONAIS ANÍSIO TEIXEIRA [INEP]. Plataformas devolutivas pedagógicas. Brasília, 14 abr. 2014. Disponível em <http://www.todospelaeducacao.org.br/reportagens-tpe/30096/483-dosprofessores-ensino-medio-tem-licenciatura-na-disciplina-que-ministram >. Acesso em: 08 fev. 2016.

RODRIGO, L. M. Filosofia na sala de aula. São Paulo: Autores Associados, 2009.

RIO DE JANEIRO (Estado). Secretaria de Estado de Educação do Rio de Janeiro. Currículo mínimo Filosofia. Rio de Janeiro, 2012. Disponível em:

<http://www.rj.gov.br/web/seeduc/principal>. Acesso em: 10 set. 2015. 